\title{
The silent somatotroph tumours
}

\section{손}

Authors: Chinezu Laura', Vasiljevic Alexandre ${ }^{2,3}$, Lapoirie Marion ${ }^{2,4}$, Trouillas Jacqueline ${ }^{2,3}$, Jouanneau Emmanuel 5 ,6, Raverot Gerald ${ }^{4,5}$ ${ }^{1}$ University of Medicine and Pharmacy, Targu Mures, Romania, ${ }^{2}$ Université Lyon 1, Lyon, F-69372, France, ${ }^{3}$ Centre de Pathologie Est, Groupement Hospitalier Est, Hospices Civils de Lyon, Bron, F-69677, France, ${ }^{4}$ Fédération d'Endocrinologie, Groupement Hospitalier Est, Hospices Civils de Lyon, Bron, F-69677, France, ${ }^{5}$ INSERM U1052; CNRS UMR5286; Cancer Research Center of Lyon 1, Lyon, F-69372, France, ${ }^{6}$ Service de Neurochirurgie, Groupement Hospitalier Est, Hospices Civils de Lyon, Bron, F-69677, France

Background: Silent somatotroph tumours are GH immunoreactive (IR) pituitary tumours without clinical and biological signs of acromegaly. In our pathological series, they represent $8 \%$ of the somatotroph tumours and $2 \%$ of all the pituitary tumours. The aim of our study was to compare the somatotroph tumours with and without acromegaly to a better characterization of these silent tumours.

Methods: Fifty-nine tumours with acromegaly and 21 silent somatotroph tumours were studied. They were classified into monohormonal (pure GH) and plurihormonal (GH/PRL/ $\pm T S H)$ and into densely (DG) and sparsely granulated (SG) types. The proliferation (Ki-67 index, mitosis count), the differentiation (expression of somatostatin receptors SSTR2A-SSTR5 and Pit-1) and the secretory activity (\% of GH IR cells) were compared in the 2 groups of patients.

Results: Tables I-II and Figures 1-3,

Table I. Clinical and pathological characterization of 80 somatotroph tumors.

\begin{tabular}{|c|c|c|c|}
\hline Clinical and pathological data & $\begin{array}{l}\text { With acromegaly } \\
(n=59)\end{array}$ & $\begin{array}{l}\text { Without acromegaly } \\
(\mathrm{n}=21)\end{array}$ & Pvalue \\
\hline \multicolumn{4}{|l|}{ Clinical data } \\
\hline Sex ratio $(\mathrm{F} / \mathrm{M})$ & $23 / 36$ & $17 / 4$ & $<0.002$ \\
\hline Age (years) & $46.2 \pm 12.4$ & $42.1 \pm 12.6$ & NS \\
\hline Size $(\mathrm{mm})$ & $17.1 \pm 8.6$ & $21.5 \pm 9.7$ & $<0.057$ \\
\hline Invasion (yes/no) & $30 / 27^{*}$ & $8 / 13$ & NS \\
\hline \multicolumn{4}{|l|}{ Pathological data } \\
\hline Monohormonal GH/Plurihormonal GH & $38 / 21$ & $5 / 16$ & $<0.01$ \\
\hline GH (\% of IR cells) & $79.4 \pm 24.5$ & $51.4 \pm 31.2$ & $<0.0001$ \\
\hline PRL ( $\%$ of IR cells) & $10.3 \pm 19.5$ & $16.2 \pm 22.4$ & NS \\
\hline $\mathrm{DG} / \mathrm{SG}$ & $32 / 27$ & $7 / 14$ & NS \\
\hline $\operatorname{SSTR}_{2 \mathrm{~A}}$ (groups $1 / 2 / 3$ ) & $9 / 19 / 31$ & $7 / 5 / 9$ & $<0.01$ \\
\hline Expression of $\mathrm{SSTR}_{2 \mathrm{~A}}$ (\% of IR cells) & $65.0 \pm 32.8$ & $56.7 \pm 37.7$ & NS \\
\hline SSTR $_{5}$ (groups $1 / 2 / 3$ ) & $15 / 22 / 22$ & $6 / 8 / 7$ & NS \\
\hline Expression of SSTR ST of IR cells) $_{5}$ & $53.4 \pm 34.9$ & $52.4 \pm 36.1$ & NS \\
\hline Mitoses & $1.4 \pm 2.2$ & $1.1 \pm 1.5$ & NS \\
\hline Ki-67 & $0.9 \pm 1.7$ & $2.3 \pm 2.9$ & $<0.01$ \\
\hline p53 & $0.6 \pm 0.9$ & $1.3 \pm 1.8$ & $<0.02$ \\
\hline Pit-1 & 100 & $91.0 \pm 16.8$ & $<0.0001$ \\
\hline Prognostic classification*/** & & & $<0.01$ \\
\hline Grade 1a (non-I, non-P) n(\%) & $22(38)$ & $9(43)$ & \\
\hline Grade $1 b$ (non-I, P) n(\%) & $5(9)$ & 4 (19) & \\
\hline Grade $2 a(1$, non-P) n(\%) & $21(37)$ & 3 (14) & \\
\hline Grade 2b (I, P) n(\%) & $9(16)$ & $5(24)$ & \\
\hline Grade 3 (metastatic) n(\%) & $0(0)$ & $0(0)$ & \\
\hline
\end{tabular}

Table II. Clinical and pathological characterization of 35 plurihormonal somatotroph tumors.

\begin{tabular}{|c|c|c|c} 
& \multicolumn{2}{|c|}{ GH/PRL } \\
Clinical and pathological data & With acromegaly* & Without acromegaly** \\
& n=21 & P value \\
& & & \\
\hline Clinical data & & $37.8 \pm 10.8$ & \\
Age & $47.5 \pm 10.1$ & $22.6 \pm 10.9$ & $<0.001$ \\
Size & $13.0 \pm 4.7$ & & \\
\hline Pathological data & & $42.1 \pm 24.9$ & $<0.0001$ \\
GH (\% of IR cells) & $78.6 \pm 14.6$ & $18.6 \pm 20.9$ & NS \\
PRL (\% of IR cells) & $28.1 \pm 24.2$ & $56.4 \pm 41.3$ & NS \\
Expression of SSTR 2 (\% of IR cells) & $67.4 \pm 32.8$ & $46.4 \pm 40.3$ & NS \\
Expression of SSTR5 (\% of IR cells) & $51.9 \pm 32.2$ & $1.3 \pm 1.4$ & NS \\
Mitoses & $1.5 \pm 1.9$ & $3.1 \pm 3.3$ & $<0.01$ \\
Ki-67 & $0.8 \pm 1.2$ & $1.4 \pm 1.7$ & NS \\
p53 & $0.9 \pm 1.2$ & $86.2 \pm 19.4$ & $<0.002$ \\
Pit-1 & 100 & 5 & NS \\
Grade 1a & 10 & 2 & \\
Grade 1b & 2 & 2 & \\
Grade 2a & 4 & 5 & \\
Grade 2b & 4 & &
\end{tabular}

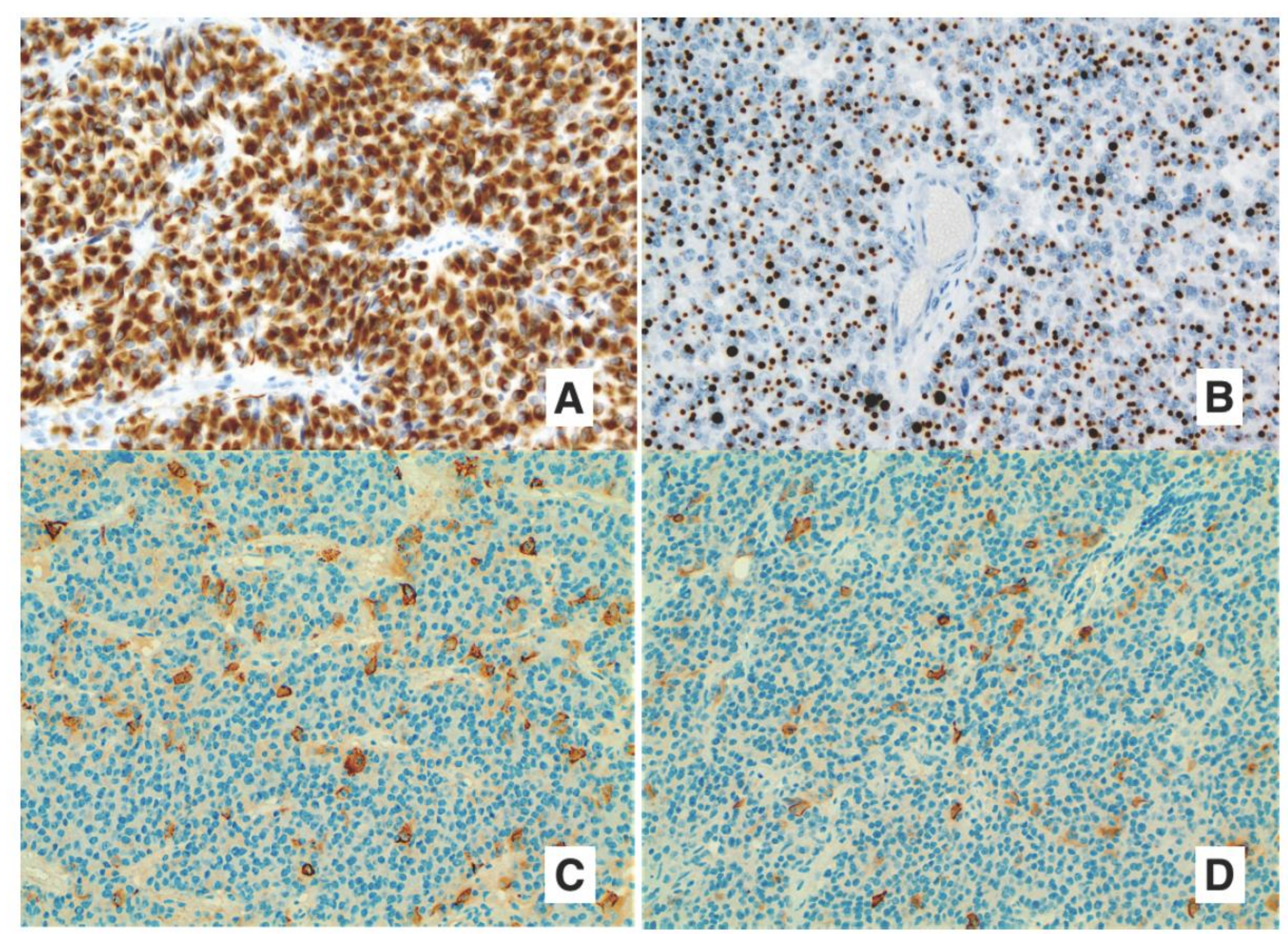

Fig 1. Immunohistochemical expression of cytokeratin (A - diffuse cytoplasmic pattern; B - fibrous body), GH (C - 30\%) and PRL (D - 10\%) in silent somatotroph tumours.

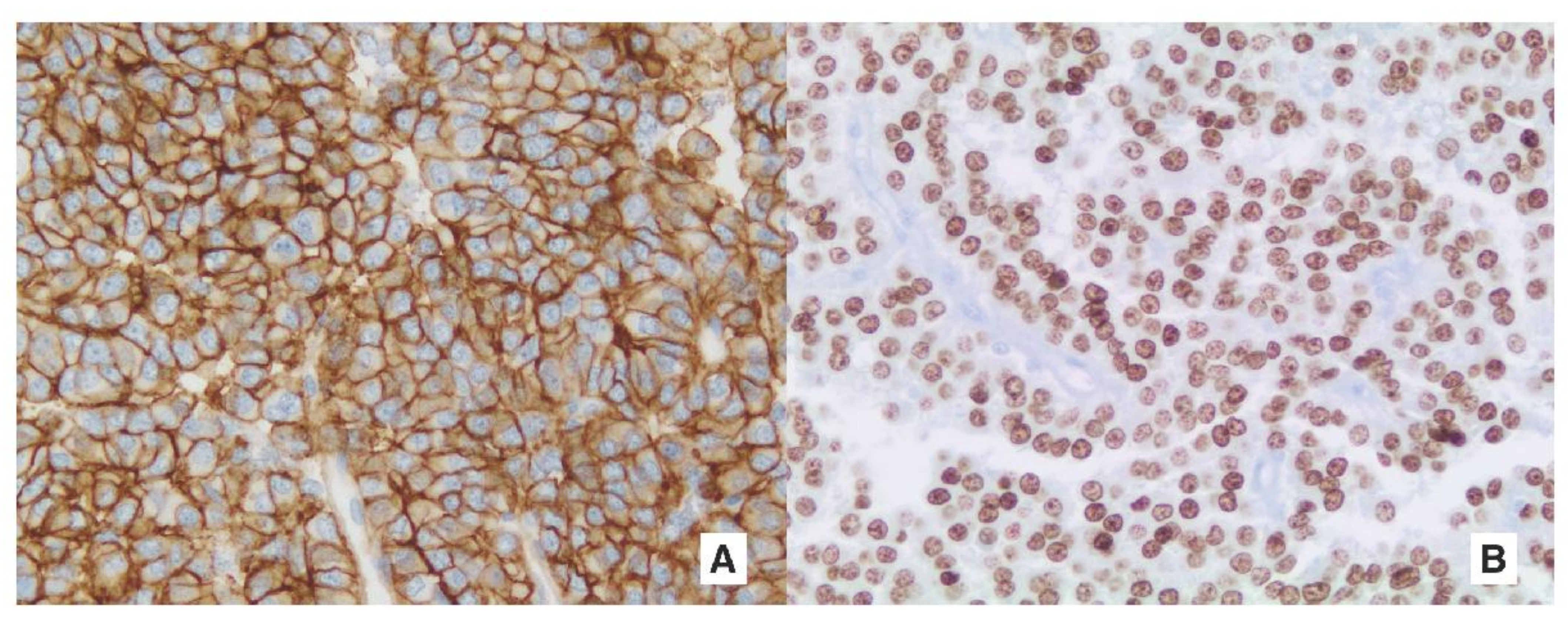

Fig 2. Immunohistochemical expression of SSTR2A (group $3-100 \%$ ) and Pit-1 (100\%) in silent somatotroph tumours.

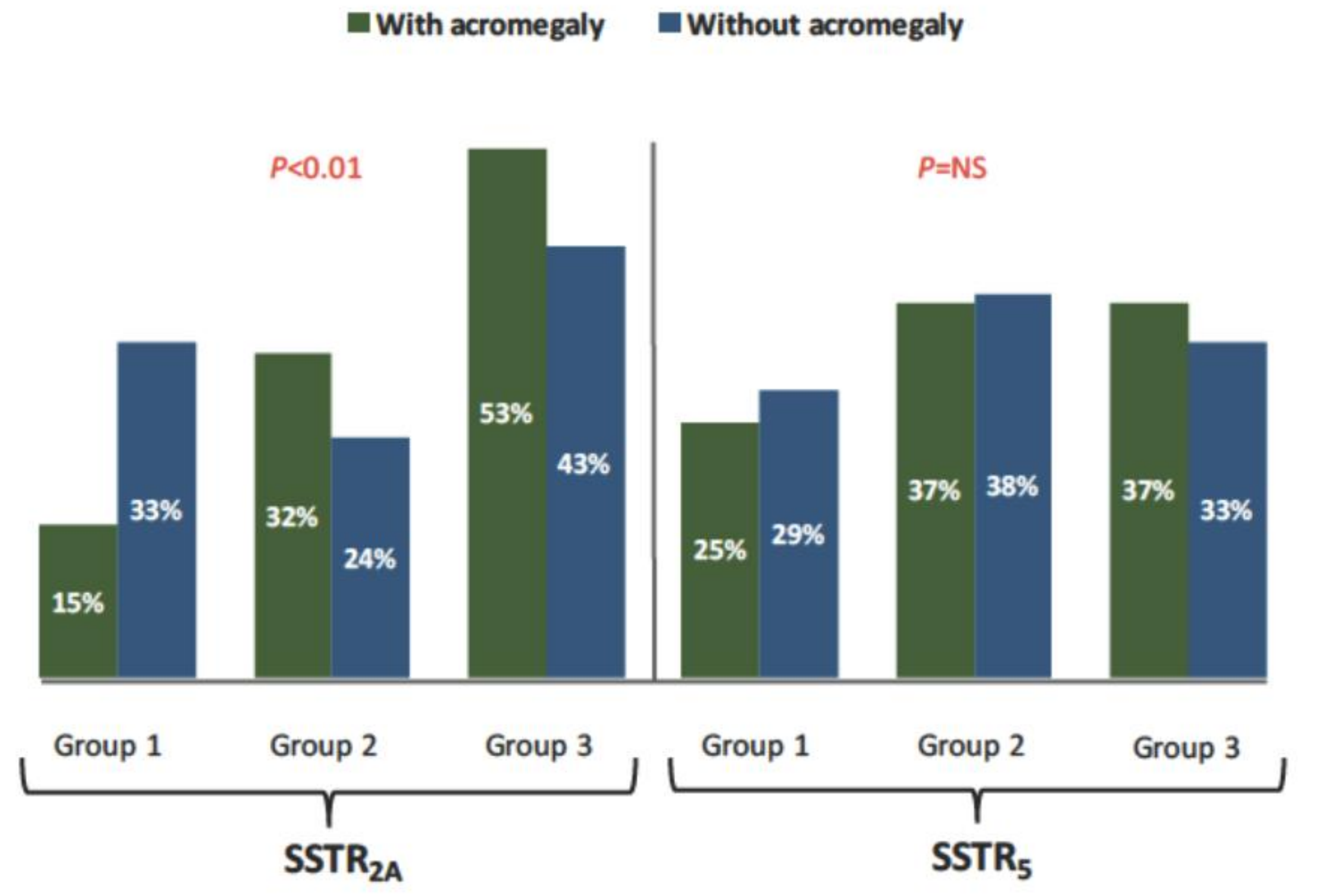

Fig 3. The expression of SSTR2A-5 in somatotroph tumors with and without acromegaly.
The silent somatotroph tumours are not rare. The age, the sex ratio, the tumour size and the grade are significantly different from the tumours with acromegaly. The monohormonal GH tumours with and without acromegaly are similar. In contrast, the silent plurihormonal tumours are less differentiated (lower \% of $\mathrm{GH}$ secreting cells, lower expression of SSTR2 and Pit1) and more proliferative than the plurihormonal tumours with acromegaly. The low secretory activity of these tumours might explain the normal plasma values of GH and IGF1 and the absence of clinical signs of acromegaly. 